\title{
Cavernous hemangioma with hematoma in the chest wall due to penetration from the anterior mediastinum
}

Hiroshige Nakamura, MD • Ken Miwa, MD

Kenichirou Miyoshi, MD · Yoshin Adachi, MD

Shinji Fujioka, MD · Yuji Taniguchi, MD

(C) The Japanese Association for Thoracic Surgery 2007

Erratum to: Gen Thorac Cardiovasc Surg

DOI 10.1007/s11748-007-0100-3

The correct name of the sixth author should be given as

Yuji Taniguchi, not Yuji Yaniguchi.

Accordingly, the contents shoud read

184 Cavernous hemangioma with hematoma in the chest wall due to penetration from the anterior mediastinum

Hiroshige Nakamura, MD · Ken Miwa, MD

Kenichirou Miyoshi, MD · Yoshin Adachi, MD

Shinji Fujioka, MD · Yuji Taniguchi, MD

The online version of the original article can be found at http://dx.doi.org/10.1007/s11748-007-0100-3

H. Nakamura $(\bowtie) \cdot$ K. Miwa $\cdot$ K. Miyoshi $\cdot$ Y. Adachi

S. Fujioka $\cdot$ Y. Taniguchi

Division of General Thoracic Surgery, Tottori University

Hospital, 36-1 Nishi-cho, Yonago, Tottori 683-8504, Japan

Tel. +81-859-38-6737; Fax +81-859-38-6730

e-mail: hnaka@grape.med.tottori-u.ac.jp 